\title{
Atitudes de Professores em Relação à Educação Inclusiva
}

\author{
Teachers' attitudes towards inclusive education
}

Actitudes de maestros con relación a la educación inclusiva

José Leon Crochík,

Cintia C. Freller,

Marian Ávila de Lima e Dias,

Marisa Feffermann,

Rafael Baioni do Nascimento \&

Ricardo Casco

Universidade de São Paulo

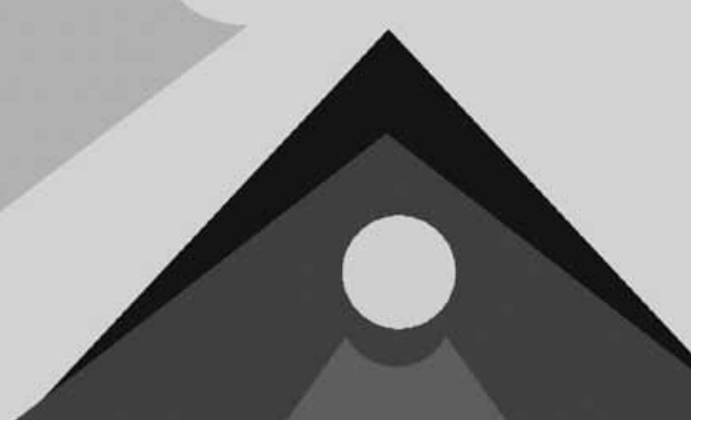


Resumo: Com a finalidade de analisar atitudes de professores em relação à educação inclusiva por meio da teoria crítica da sociedade, entrevistamos 14 professores do ensino fundamental. A maioria dos entrevistados se declarou favorável à educação inclusiva, propondo condições adequadas tais como: recursos humanos, diminuição de alunos em sala, restrição ao número de alunos com deficiência intelectual, necessidade de o professor ser especialista em educação inclusiva, participação de outros especialistas (médicos, psicólogos, fonoaudiólogos etc.) e apoio de outro professor em sala. No que se refere aos benefícios e prejuízos da educação inclusiva, verificou-se que a maioria dos professores julga que os alunos sem deficiência se consideram superiores àqueles que não têm deficiência, metade dos entrevistados julga que a presença dos alunos com deficiência não atrapalha a aprendizagem dos alunos sem deficiência, e, por fim, que a maioria dos professores considera que a educação inclusiva deve favorecer a socialização e a aprendizagem dos alunos com deficiência.

Palavras-chave: Educação integrada/inclusiva. Teoria crítica da sociedade. Atitudes. Professores.

Abstract: In order to analyze the attitudes of teachers towards inclusive education by means of the critical theory of the society, 14 elementary school teachers with and without experience with this type of education were interviewed; the teachers worked in public and private schools. The majority of the people interviewed declared they were favorable to the inclusive education considering appropriate conditions such as: human resources, reduction of students in class, restriction to the number of students with intellectual disability, the necessity of the teacher to be an specialist in inclusive education and the presence of health professionals (such as doctors, psychologists and fonoaudiologists) in the school as well as the support of other teachers in class. As for the benefits and damages of the inclusive education, the results showed that the majority of the teachers thinks that the students without disability consider they are superior to the classmates with disability and half of the interviewed think that the presence of the students with disability does not disturb the apprenticeship of the students without disability; eventually, the majority of the teachers considers that the inclusive education favor both socialization and learning of the students with disability.

Keywords: Integrated/ inclusive education. Critical theory of the society. Attitudes. Teachers.

Resumen: Con la finalidad de analizar actitudes de maestros con relación a la educación inclusiva por medio de la teoría crítica de la sociedad, entrevistamos 14 profesores de la enseñanza fundamental. La mayoría de los entrevistados se declaró favorable a la educación inclusiva, proponiendo condiciones adecuadas tales como: recursos humanos, disminución de alumnos en sala, restricción al número de alumnos con deficiencia intelectual, necesidad de que el profesor sea especialista en educación inclusiva, participación de otros especialistas (médicos, psicólogos, fonoaudiólogos etc.) y apoyo de otro maestro en sala. En lo que se refiere a los beneficios y perjuicios de la educación inclusiva, se verificó que la mayoría de los maestros juzga que los alumnos sin deficiencia se consideran superiores a aquellos que tienen deficiencia, la mitad de los entrevistados juzga que la presencia de los alumnos con deficiencia no estorba el aprendizaje de los alumnos sin deficiencia, y, por fin, que la mayoría de los maestros considera que la educación inclusiva debe favorecer la socialización y el aprendizaje de los alumnos con deficiencia.

Palabras clave: Educación integrada/inclusiva. Teoría crítica de la sociedad. Aptitudes. Maestros.

O movimento social ligado à educação inclusiva encontra-se historicamente relacionado à luta por direitos civis, sobretudo ao que é conhecido pela inclusão daqueles que são segregados ou marginalizados pela sociedade. Na Itália, por exemplo, segundo Sanz del Rio (1996), está associado ao movimento conduzido por Franco Basaglia que visava ao fim dos hospitais psiquiátricos.
De acordo com alguns autores (Horkheimer \& Adorno, 1947/1985; Martins, 1997), a estrutura de nossa sociedade é responsável pela constante exclusão de vários grupos. $\mathrm{Na}$ análise da sociedade capitalista do século XIX, Marx (1867/1984) evidencia a marginalização dos trabalhadores do sistema social e a segregação dos que formam o exército industrial de reserva. Os trabalhadores, 
Segundo Adorno (1959/1972), os homens passaram a se assemelhar entre si no nível sociopsicológico, mas não nas condições objetivas. além das condições de esgotamento físico e psíquico no trabalho, principalmente a partir do desenvolvimento da maquinaria industrial, viviam em condições precárias e prejudiciais à sua saúde. A partir do desenvolvimento das máquinas, mulheres e crianças adentram no mundo do trabalho e passam a ser exploradas pelo capital. As crianças não tinham condições sequer de serem educadas. Para que alguns pudessem ter uma vida confortável e cultivada, uma parcela ampla da população tinha de se contentar com a sobrevivência e ser feliz quando conseguisse encontrar um emprego.

Apesar do ímpeto político, expresso nos movimentos do século XIX - as comunas francesas, por exemplo - e no surgimento de regimes socialistas no século XX, o proletariado não se emancipou. Ao contrário, segundo Marcuse (1964/1982), os trabalhadores foram integrados à sociedade e passaram a ser parceiros do capital. Segundo Adorno (1959/1972), os homens passaram a se assemelhar entre si no nível sociopsicológico, mas não nas condições objetivas. A ideologia da integração, conforme denominação de Adorno, não admite que alguém fique de fora: a previdência social deve alcançar todos (ver Horkheimer \& Adorno, 1947/1985).

Na esfera da educação, as camadas mais pobres da população passaram a ser contempladas com o que só era oferecido à elite social, mas ao preço de serem reduzidas a mercadoria. A produção do ensino de massa, quer em seus meios - formação de professores, produção de livros didáticos e de instrumentos educacionais - quer em seus fins - a produção de cidadãos padronizados, dotados de um mesmo mínimo necessário para expressar o que todos expressam, não se volta para a diferenciação individual, que surge com a incorporação da cultura; como essa não é incorporada, mas instrumentalizada (ver Adorno, 1969/1995), continua externa aos indivíduos. A tecnologia não deixou de adentrar a educação, que, em seu ímpeto de formar para a competência, criou métodos e simplificou conhecimentos, de sorte a se poder prescindir dos professores, transformouse em transmissora de informações e não mais propícia à formação que vai além do que existe. Isso está coerente com a descrição de Benjamin (1938/1989) sobre a transformação da experiência em vivência, ao longo do século XIX: a vivência não deixa marcas no indivíduo, e, segundo Adorno (1959/1972), as informações são logo substituídas por novas: tem-se que estar a todo o momento atualizado, mas, como o conhecimento necessário para lidar com as máquinas - quer materiais, quer humanas - é logo ultrapassado, e a experiência que não pode prescindir do preceito kantiano: "um eu que acompanha todas as minhas representações" não tem lugar, surgem indivíduos fragilmente constituídos. A formação de indivíduos se converte em pseudoformação. A pseudoformação se expressa em duas tendências não antagônicas: a formação para a adaptação e a formação pela formação. A primeira tem como meta principal a formação do indivíduo para o mercado de trabalho, para o mundo existente, mas não para uma vida que já seria possível de ser vivida objetivamente; nessa modalidade de pseudoformação, a possibilidade de se pensar que a sociedade existente é produto da História e, portanto, que é modificável, não é grande, e o indivíduo é preso ao existente; no outro tipo de pseudoformação, a cultura perde também a sua relação com a História por não ser associada com as necessidades dos homens, e converte-se em mercadoria, posto que as pessoas tentam adquiri-la para ter e dar a impressão de que estão incluídas por estarem atualizadas.

Segundo Horkheimer e Adorno (1947/1985) e Marcuse (1955/1981), a exigência do trabalho, sobretudo manual, para a reprodução da espécie já não é necessária na medida em que é feita, tendo em vista o desenvolvimento das forças produtivas. 
O desenvolvimento da tecnologia, do conhecimento, da riqueza, contudo, não "arrebentou" as relações de produção capitalistas, tal como Marx (1867/1984) previu; ao contrário, ao ser incorporado por essas, torna o progresso um contínuo sem fim que serve predominantemente a um uso político para manter os interesses sociais dos mais fortes, ainda que traga benefícios a todos (ver Adorno, 1964/1995). A educação escolar para o trabalho se torna anacrônica, e o nível de escolaridade exigido para algumas funções no mercado quase não guarda relação com o que se necessita efetivamente no trabalho. Segundo Lessa et al. (1997), pessoas com título universitário atuam em atividades que poderiam prescindir desse título. Além disso, com o fim da necessidade objetiva do trabalho, segundo Marcuse (1955/1981), são criados "trabalhos sem ocupação", isto é, sem utilidade social além de empregar pessoas. Se as necessidades são historicamente criadas, nos últimos tempos, elas quase não têm mais relação com a necessidade de o homem se tornar homem, isto é, poder se valer de produtos materiais e espirituais que o levem a viver uma vida civilizada: as mercadorias produzidas têm se relacionado com necessidades psíquicas infantis (pré-genitais) de mero consumo, sem que esse consumo seja discriminado; assim, as mercadorias podem se suceder rapidamente umas às outras, posto que não produzem diferença e não fazem falta ao consumidor, a não ser para que seja um "escravo feliz".

No plano político, paulatinamente, o estado do bem-estar social, criado pelo capitalismo ocidental para competir com o socialismo, cede lugar ao neoliberalismo, que, ao contrário do liberalismo, segundo Apple (2002), não prega mais a liberdade do mercado, mas a função fiscalizadora do Estado.
Dentro desse quadro de modificações sociais é que os movimentos das minorias devem ser entendidos. O capital já se reproduz a si mesmo sem muita necessidade dos homens, e assim, a questão da competência quase não mais existe. A organização da produção pode ficar a cargo de um sistema de administração eficiente que pode prescindir da ação autônoma dos homens. Se Marx (1867/1984) pôde indicar que, com o desenvolvimento da maquinaria, o trabalhador passa a se tornar mero apêndice, com o desenvolvimento da tecnologia, ele se torna facilmente substituível por muitos outros, e essa fungibilidade se espraia para as outras esferas de vida, entre elas a educação.

Se houve o declínio da necessidade do trabalho devido ao avanço das forças produtivas, a educação voltada para o desenvolvimento das competências é anacrônica, quando o mundo do trabalho atinge o grau de automação obtido. É claro que, nos últimos tempos, devido à crescente violência, sobretudo nos países em desenvolvimento, defende-se a educação. Numa sociedade que exige a competição entre os homens e que não pode dar uma vida digna a todos, no entanto, por mais que a educação atue contra a violência, se essa não for discutida politicamente, cai em contradição, posto que enfatiza a paz quando o conflito é continuamente suscitado.

Se a educação inclusiva se fortalece, principalmente, a partir da década de 1990 (ver Sanz del Rio, 1996), ela não ameaça o que no passado era relevante: a formação dos indivíduos para o trabalho, uma vez que, como visto, esse não é mais necessário como o era antes. De outro lado, como se trata de pseudoformação, mesmo a educação dada não deve possibilitar, no limite, o entendimento do que leva essas mesmas minorias incluídas poderem ser novamente excluídas. 
O movimento do esclarecimento, no entanto, é contraditório, e não deve produzir somente regressão social e individual, mas também progresso. Nesse sentido, é certo que mesmo o que ainda pode ser transmitido pelas escolas deve ser valorizado. O que se pode fazer é, segundo Adorno (1967/1995), insistir na escola para que a educação seja voltada para a resistência à opressão dos homens, para que seja uma educação que leve à percepção das contradições sociais, e não para negá-las. Claro, somente com a educação não é possível modificar a sociedade, não obstante, por meio dela, é possível fortalecer a consciência para que essa se oponha à violência.

Nesse sentido, a educação inclusiva, que propõe a modificação da escola para que possa superar os obstáculos à aprendizagem (Booth \& Ainscow, 2002), pode, pelo convívio entre diferentes minorias, combater o preconceito e a conseqüente discriminação. Certamente, o preconceito tem uma dimensão não consciente, o que indica que o mero convívio talvez não seja suficiente para eliminá-lo, mas o contato com o seu alvo pode diminuir a violência que recai sobre ele (ver Vala \& Monteiro, 1996).

Do que foi escrito até o momento, entendemos que a implantação da educação inclusiva é importante na luta por uma sociedade mais justa, mas não devemos desconsiderar os limites da educação atual no que se refere à formação, devido às próprias condições objetivas. Isso implica a necessidade de mais do que somente a inclusão das minorias antes segregadas da escola regular, a necessidade de nos preocuparmos também com a qualidade da educação e com o quanto esta atualmente contribui para formar indivíduos efetivamente críticos. Se a crítica se relaciona com a possibilidade de uma sociedade mais justa, e, se possível, justa, o convívio com minorias discriminadas já se constitui em um elemento formador. O papel do professor para essa formação é fundamental, pois não se trata unicamente de transmitir conhecimentos, mas da forma como o faz e de sua relação com o saber. A forma de transmissão aqui entendida não se refere somente a técnicas, por mais que estas sejam imprescindíveis, mas ao engajamento do professor, à sua cumplicidade com o aprendizado do aluno, isto é, refere-se a princípios políticos e éticos. Os dados da pesquisa de Casco (2007) e sua análise mostram que a forma de os professores incentivarem a participação dos alunos em sala de aula, seus elogios e críticas ao desempenho e ao comportamento dos alunos está relacionada com a formação de grupos e, assim, a forma pela qual os professores possam atuar junto aos alunos com deficiência não é indiferente para o grupo de alunos. Dessa maneira, o modo como os alunos se relacionam entre si, com maior ou menor grau de discriminação, também depende da forma de atuação dos professores para com todos os seus alunos.

Algumas pesquisas mostram a importância do professor na educação inclusiva. Segundo Cook, Tankersley, Cook e Landrun (2000), os alunos com dificuldades de aprendizagem em geral tendem a ser rejeitados por parte dos seus professores, e eles propõem que a atitude do professor seja considerada na implantação e no desenvolvimento do ensino inclusivo. Conforme esses autores, os comportamentos menos adequados de alguns alunos e seu aprendizado mais lento podem gerar atitudes desfavoráveis dos professores em relação a eles. León (1994) também se preocupa com a dificuldade dos professores em sua relação com alunos que tenham necessidades educativas especiais e propõe estudos acerca de fatores que possam afetá-los em sua relação com esses alunos.

Beyer (2005) cita pesquisa na qual houve entrevistas com professores com experiência em educação inclusiva e concluiu que, em geral, essa experiência diz respeito mais à 
educação integrada do que à educação inclusiva, e que alguns poucos professores são favoráveis à educação segregada. A distinção entre educação integrada e educação inclusiva é dada, entre outros, por Vivarta (2003), que indica que a primeira aceita os alunos com deficiência, faz algumas alterações importantes quer nas condições ambientais, quer na atenção a esses alunos, mas não faz modificações substanciais que incidam sobre todos os alunos, que é o caso da educação inclusiva, que propõe novas modalidades de ensino que dão ênfase a trabalhos em grupo, ao desenvolvimento de currículos diferenciados para os alunos e avaliações também distintas, isto é, torna a escola mais apta a atender todos os alunos (ver Mittler, 2003). A escola da Ponte, dirigida por Pacheco (Pacheco, Eggertsdóttir, \& Marinósson, 2007), é uma ilustração de educação inclusiva. Nessa escola, as atividades grupais cooperativas são predominantes. Nas experiências descritas por esses autores, um tema é escolhido pela classe, que se divide em grupos cada vez diferentes, que dividem o trabalho entre si, e o conteúdo curricular é apresentado na medida em que é necessário. Pacheco et al. (2007) descrevem algumas das características dessa escola:

Na escola da Ponte, o ensino baseado na sala de aula tradicional com um professor tem, desde 1976, sido substituído por um sistema de ensino e aprendizagem centrado em pequenos grupos e nos ritmos de cada aluno. Não há métodos diferentes para as crianças consideradas deficientes, pois cada aluno é tratado como especial. Da mesma forma, as adaptações curriculares são feitas para todos os alunos. A comunicação e o trabalho em equipe são priorizados. Todos os professores são professores de todos os alunos, e todos os alunos são alunos de todos os professores. Os grupos de alunos são heterogêneos, e não, baseados em notas. Em cada grupo, o gerenciamento do tempo e do espaço permite um trabalho cooperativo, tutoria por pares e momentos de trabalho individual. O centro da vida escolar é a assembléia escolar que acontece semanalmente. É aí que projetos comuns são elaborados e que os conflitos são resolvidos. (p. 21)

Se a pesquisa de Beyer (2005) traz dados acerca de professores com experiência no processo de inclusão escolar, Monteiro e Castro (1997) mostram que as expectativas de alunos com experiência com colegas com deficiência e os que não possuem essa experiência são distintas. Na pesquisa que relatam, paradoxalmente, os alunos com experiência com colegas com deficiência intelectual apresentaram uma atitude mais contrária a esse aluno do que aqueles que não tinham essa experiência. Esse resultado levou as autoras a supor que o mero contato de um aluno com deficiência com os demais não bastava, e que seriam necessárias outras interferências para que esse aluno pudesse ter uma imagem mais favorável por parte dos colegas. Certamente, o professor é o principal agente em sala de aula, e depende de suas atitudes boa parte do que possa afetar as dos alunos sem deficiência em relação àqueles que as têm. Assim, não basta a experiência do contato com alunos com deficiência para que algum grau de inclusão ocorra; é necessária também a intervenção conseqüente do professor.

Se na educação, de uma forma geral, a distinção entre o ensino público e privado é importante, isso também deve ocorrer no que se refere à educação inclusiva. De fato, mesmo em países desenvolvidos, essa diferença se faz presente. Na Espanha, as escolas privadas também são financiadas pelo Estado, segundo diz Enguita, em sua entrevista publicada em Zibas (1999), e essas escolas tentam evitar o ingresso de alunos considerados problemáticos: 
É verdade que as escolas privadas financiadas com dinheiro público recusam os alunos problemáticos. Não podem fazer isso formalmente, mas fazem de maneira velada, e o alunado mais problemático vai para as escolas públicas... Fora isso, o que existe é uma concentração maior de minorias nos centros públicos. Agora, olhando de perto, a única diferença é a seguinte: tanto os colégios privados como os públicos tentam não aceitar esse tipo de aluno. O que acontece é que, nos colégios privados, quem decide é o diretor; nos colégios públicos, é o inspetor. A administração central é capaz de imporse aos colégios públicos, mas não aos privados. (p. 241)

No Brasil, acerca dessa questão, Jannuzzi (2004) mostra que, à medida que a escola vai incluindo indivíduos antes marginalizados ou segregados, vai se tornando dual: escolas para pobres e escolas para ricos, o que quase coincide, em nosso meio, com escolas públicas e escolas privadas. Nesse sentido, cabe a pergunta se a educação inclusiva no ensino público e no ensino particular é semelhante no Brasil.

Em pesquisa realizada com futuros professores, alunos de licenciatura, Crochík, Ferrari, Hryniewicz, Barros e Nascimento (2006) coletaram dados cuja análise indicou haver relação entre preconceito e atitude contra a educação inclusiva; ainda que a correlação obtida tenha sido significativa, a sua magnitude não foi elevada, o que pode indicar que, como a discussão é recente e tampouco é ampla, não haja, até o momento, posição formada a respeito da educação inclusiva por boa parte dos sujeitos pesquisados.

Como já foi enunciado, há diversas tendências em relação à educação inclusiva. Booth e Ainscow (2002) consideram que há um contínuo de implementação no que se refere à educação inclusiva, e assim criaram um Index com a finalidade de que as escolas, se assim o desejarem, saibam que outros obstáculos podem ser suplantados para que elas se tornem mais inclusivas. Chama a atenção, nesse trabalho, que alguns indicadores de educação inclusiva sejam: esperar e exigir o máximo possível dos alunos, só excepcionalmente indicar um assistente, em sala de aula, para auxiliar um aluno específico, o combate à discriminação de quem quer que seja e a ação conjunta dos professores e dos alunos e especialistas que compartilhem seu saber com a escola. Uma escola que tenha alunos com deficiência, mas que não faça as alterações necessárias nos métodos de ensino e de avaliação no ambiente físico e, sobretudo, na atuação de docentes, discentes e funcionários da escola, seria pouco inclusiva.

Outro aspecto importante a ser mencionado no que se refere à questão da educação inclusiva é o de transmissão de conhecimentos ou a formação e o desenvolvimento de habilidades nos alunos com necessidades educativas especiais que talvez possam ser consideradas menos relevantes do que a socialização. Na década de 1960, em um debate entre Becker e Adorno (Adorno, 1969/1995), o primeiro, ao se referir à filha do presidente Kennedy, argumenta que o destaque dado com euforia é o de que ela estaria bem adaptada, o que levou ambos a criticarem a forma predominante de educação, que tem como meta a adaptação à sociedade e descuida da formação de indivíduos emancipados. Ora, se a inclusão escolar não significar também o máximo desenvolvimento possível das capacidades intelectuais, ela será apenas a máscara para a marginalização dentro de sala de aula. Deve-se considerar também, em relação a essa questão, que os alunos sem necessidades educativas especiais não gostam que haja discriminação entre eles por parte dos professores. Pela análise de 20 pesquisas que estudaram as atitudes de alunos de classes regulares, que incluíam estudantes 
com necessidades educacionais especiais, Klingner e Vaughn (1999) concluíram que os alunos com ou sem dificuldades querem tratamento igual dos professores e da escola, isto é, querem que todos sejam submetidos às mesmas atividades, aos mesmos livros e tenham as mesmas atividades de grupo. Eles não se importam que o professor adapte métodos ou despenda mais tempo para explicar algo para os alunos que não conseguiram entender determinado assunto, mesmo porque, segundo eles, assim têm chances de aprender mais e melhor. Gostam de auxiliar os colegas que têm mais dificuldades e, com exceções, preferem o trabalho em grupo que contenha alunos com e sem dificuldades. Assim, a educação inclusiva não deveria se preocupar somente com a questão da socialização, pois, além do que informa o trabalho de Klinger e Vaughn, se o indivíduo se forma por meio da incorporação da cultura (ver Adorno, 1959/1972), ela deve ser transmitida para que todos possam se diferenciar por meio dela.

Considerando a importância do professor na educação inclusiva, sua experiência com alunos de inclusão e o fato de trabalhar em escolas públicas ou particulares, o objetivo da pesquisa aqui relatada foi comparar professores desses dois tipos de escola com e sem a experiência referida quanto à posição acerca da educação inclusiva, à atitude acerca dos benefícios e prejuízos para os alunos da educação inclusiva e a atitude a respeito das condições necessárias para a implementação da educação inclusiva.

Supomos que haja um contínuo entre os quatro grupos de professores comparados, sendo que os de escolas particulares com experiência talvez sejam mais favoráveis à educação inclusiva, explicitem mais benefícios e menos condições para que seja bem sucedida. Na seqüência desse contínuo, estariam os professores de escola pública com experiência, os professores de escolas particulares sem experiência e, por fim, os professores de escolas públicas sem experiência com educação inclusiva.

\section{Método}

Participantes: fizeram parte deste estudo 14 professores do ensino fundamental de primeiro ciclo, divididos em quatro grupos, sendo: quatro professores com experiência em educação inclusiva que atuam em escolas particulares (G1), três professores sem experiência em educação inclusiva que atuam em escolas particulares (G2), quatro professores com experiência em educação inclusiva que atuam em escolas públicas (G3) e três professores sem experiência em educação inclusiva que atuam em escolas públicas (G4). Dos entrevistados, 12 são do sexo feminino e 2 do sexo masculino (um professor no G1 e outro no G3).

A Tabela 1 contém as medianas referentes à idade e ao tempo de formação superior dos sujeitos por grupo.

Tabela 1. Medianas da idade dos professores e do tempo de formação no ensino superior .

\begin{tabular}{llllll}
\hline & G1 & G2 & G3 & G4 & Geral \\
\hline Idade & 29 & 33 & 42 & 32 & 32 \\
Tempo de formação & 6 & 7 & 8 & 8 & 7 \\
& & & & & \\
\hline
\end{tabular}


Pode-se observar, pela Tabela 1, que os sujeitos do G3 têm a mediana da idade maior do que os sujeitos dos outros grupos, e que as medianas do tempo de formação são semelhantes nos diversos grupos.

Quanto à formação, todos os professores do G1 têm o curso de Pedagogia completo, assim como dois professores do G2 e três do G3. Um professor do G3 e dois do G4 estão cursando Pedagogia. Dois professores têm formação superior incompleta: um professor do G2 (Normal Superior) e um do G4 (superior em Artes).

Instrumento: roteiro de entrevistas

A base para a elaboração do roteiro de entrevista foi a Escala de Atitudes frente à Educação Inclusiva (E) empregada em trabalho anterior (Crochík et al., 2006). As 11 afirmações dessa escala foram divididas em três fatores: posição frente à educação inclusiva, benefícios e prejuízos da educação inclusiva para os alunos e condições necessárias para a implementação da educação inclusiva; a esses fatores, foram acrescentadas questões acerca de dados de identificação e formação dos professores. O roteiro foi testado em duas entrevistas com sujeitos com características similares aos desta pesquisa.

Procedimento de coleta de dados

Inicialmente, procuramos escolas (públicas e particulares) regulares que tinham experiências com alunos com deficiência intelectual e as que não a tinham. Contatamos os professores e agendamos a entrevista. $\mathrm{Na}$ entrevista, garantimos o anonimato dos sujeitos. As entrevistas foram individuais e realizadas por duplas de pesquisadores, e um deles se encarregou de formular as questões do roteiro e as outras, provenientes das respostas do entrevistado, e o outro anotava suas observações e cuidava da gravação em áudio. As transcrições foram feitas separadamente pela dupla de entrevistadores e depois confrontadas entre si. Como parte dos sujeitos tinha experiência em educação inclusiva e a outra parte não, aos primeiros, a entrevista deu ênfase às experiências que tiveram, e, aos últimos, solicitamos que pudessem imaginar quais seriam os obstáculos e/ou benefícios dessa modalidade de educação. Depois de os pesquisadores terem lido todas as transcrições, foram retirados do texto os vícios de linguagem, as repetições de expressões ou eventuais erros de concordância presentes na primeira transcrição. Essas transcrições foram enviadas aos entrevistados para que eles pudessem fazer as alterações que julgassem necessárias.

Procedimentos para a análise dos dados

Cada entrevista foi organizada segundo os dados de identificação e em conformidade com os três fatores enunciados anteriormente, dois dos quais subdivididos em itens: Fator 1 - posição frente à educação inclusiva; Fator 2 - benefícios e prejuízos da educação inclusiva para os alunos, com os itens: imitação e sentimento de superioridade dos alunos sem deficiência intelectual em relação aos alunos com essa deficiência, e se os alunos com deficiência intelectual atrapalham a aula; Fator 3 - condições necessárias para a implementação da educação inclusiva, com os itens: condições gerais; número de alunos total e número de alunos com deficiência intelectual em sala de aula; necessidade ou não de o professor ser especialista, posição frente ao especialista de apoio e ao auxílio em sala, e os objetivos da educação inclusiva.

Os trechos mais significativos das entrevistas foram agrupados dentro dos três fatores. Além da separação em fatores previamente eleitos, a análise das transcrições também contemplou elementos, presentes nas falas dos professores entrevistados, que não constavam no roteiro e 
que, contudo, chamaram a atenção. Foi o caso da questão dos objetivos da educação inclusiva, em que as idéias de socialização e de aprendizagem foram freqüentemente mencionadas pelos entrevistados. Esse agrupamento foi realizado por duplas de pesquisadores: um deles realizou a escolha desses trechos, enquanto o outro verificou se eram os mais adequados, recorrendo à íntegra da transcrição do professor entrevistado para realizar a comparação. O produto final dessa etapa resultou em uma síntese de cada entrevista. As sínteses dos 14 entrevistados foram lidas por todos os pesquisadores. A partir dessas sínteses, as respostas selecionadas foram agrupadas em categorias referentes aos fatores anunciados. Inicialmente, cada pesquisador, com base na síntese das entrevistas dos professores, preencheu a tabela. Posteriormente, foram confrontadas as respostas tabuladas individualmente a fim de verificar alguma discrepância. Após a correção de eventuais diferenças na categorização das respostas dos professores, a íntegra da entrevista foi relida por um dos pesquisadores para nova confirmação das respostas tabuladas.

\section{Resultados}

Deve-se ressaltar, de início, que a amostra de entrevistados desta pesquisa não é representativa da população segundo os critérios estatísticos, uma vez que são poucos os professores entrevistados, e estes não foram sorteados dentre a população à qual pertencem. Deve-se considerar, porém, que os dados obtidos sintetizam respostas abertas dos sujeitos, o que lhes confere maior precisão quando comparados, por exemplo, com respostas dadas a uma escala, uma vez que no lugar de os sujeitos responderem a alternativas, as suas respostas foram categorizadas a partir de várias informações obtidas em suas entrevistas. A análise dos dados que será apresentada a seguir deve considerar que analisamos tendências, sem poder afirmar o quanto elas são expressivas ou não da população, ainda que essas tendências sejam provenientes de fatores objetivos e se expressarem como suposição de que poucos são os seus integrantes neste momento, mas que, em um outro momento, podem ser fortalecidas; o mesmo deve ser considerado se essas tendências expressarem a atitude de muitas pessoas. Os dados apresentados a seguir serão discutidos segundo os fatores que organizaram as questões e as respostas das entrevistas.

\section{Posição frente à educação inclusiva}

A Tabela 2 contém a freqüência de respostas, por grupo, referente à posição que os sujeitos têm em relação à educação inclusiva.

Tabela 2. Respostas favoráveis e desfavoráveis à educação inclusiva por grupo.

\begin{tabular}{llllll}
\hline & G1 & G2 & G3 & G4 & Total \\
\hline Favorável & 4 & 3 & 3 & 2 & 12 \\
Desfavorável & 0 & 0 & 1 & 1 & 2 \\
Total & 4 & 3 & 4 & 3 & 14 \\
\hline
\end{tabular}

Pelos dados da Tabela 2, observa-se que a maioria dos entrevistados se declarou favorável à educação inclusiva, com apenas duas exceções, ambas de professores de escolas públicas. 
Como são poucos os sujeitos da amostra, chama a atenção o detalhe de que os dois professores desfavoráveis sejam de escolas públicas, ainda que, mesmo nesse grupo, sejam minoria.

O fato de a maioria dos professores entrevistados ser favorável à educação inclusiva é importante do ponto de vista político, posto que mostra a disposição dos professores em aceitar alunos diferençados em comparação aos que estão acostumados a ensinar. Talvez esse resultado se deva, sobretudo nos sujeitos que não têm experiência na área, ao desejo de obterem a aprovação dos entrevistadores em relação a uma questão que tem apoio cultural; por outro lado, a garantia do anonimato e a postura dos entrevistadores de evitar, ao máximo, qualquer julgamento das respostas dos entrevistados pode ter atenuado esse desejo. Mesmo que alguns sujeitos tenham dado uma resposta "politicamente correta" em sua manifestação favorável à educação inclusiva, esse posicionamento ao menos possibilita o convívio de crianças com e sem deficiência e a discussão a respeito dessa convivência.

Se a educação inclusiva é um modo de se combater a discriminação e o preconceito, o fato de os sujeitos, em sua maioria, manifestarem posição favorável a ela é relevante. Certamente, tal como aprendemos com Freud (1930/1969), se uma forma de manifestação de desejos é proibida, ela encontra outras formas de aparecer, mas, com o mesmo autor, aprendemos também que há sintomas mais ou menos comprometedores para a vida do indivíduo, o que permite inferir que, se o preconceito deve continuar a existir sob formas de marginalização e segregação em sala de aula, essas formas de discriminação, que também devem ser combatidas, ao menos permitem o contato entre o algoz e sua vítima e, em alguns casos - o dos indivíduos que tenham o preconceito menos arraigado - , isso pode ser o suficiente para que aquele desapareça ou diminua.

Em suma, ainda que a posição favorável à educação inclusiva manifestada pela maioria dos sujeitos talvez possa não ser expressão do que de fato pensam, mesmo assim, é um dado politicamente importante para a implementação desse tipo de educação e para o cumprimento de seus objetivos.

Esse dado não nos permite afirmar, por si só, qual é a posição dos professores em relação a possíveis dificuldades encontradas no cotidiano que reúne alunos com condições diversas de aprendizado. Alguns elementos acerca dessa posição poderão ser encontrados na análise dos outros fatores, que será apresentada a seguir.

\section{Benefícios e prejuízos da educação inclusiva}

Na Tabela 3, encontram-se as freqüências de respostas dos entrevistados a respeito de sua percepção quanto aos alunos imitarem os que têm deficiência intelectual.

Tabela 3. Respostas da percepção dos professores em relação aos alunos imitarem os colegas com deficiência.

\begin{tabular}{llllll}
\hline & G1 & G2 & G3 & G4 & Total \\
\hline Sim & 1 & 0 & 1 & 0 & 2 \\
Não & 1 & 1 & 2 & 0 & 4 \\
Não cita & 2 & 2 & 1 & 3 & 8 \\
Total & 4 & 3 & 4 & 3 & 14 \\
\hline
\end{tabular}


Segundo os dados da Tabela 3, são apenas dois os entrevistados que julgam que alunos sem deficiência imitam os que têm deficiência intelectual, ambos professores com experiência com esse tipo de aluno. Outros quatro responderam que não observaram essa imitação. Chama a atenção, também, o fato de a maior parte dos professores não ter se pronunciado em relação a essa questão e o fato de não haver nenhuma tendência dos dados que diferencie os grupos.

Essa é uma informação importante, posto que responde ao temor existente, principalmente da parte dos pais dos alunos sem deficiência, de que os alunos com deficiência possam ser má influência. Pelo estudo de Klingner e Vaughn (1999), é o contrário que se pode inferir em relação a esses alunos: eles tendem a ser modelos para os que têm deficiência, por serem valorizados pelos professores e pais.

Esses dados podem indicar que os alunos que têm deficiência intelectual não são ridicularizados por meio de uma imitação grotesca. Deve-se salientar que, apesar de os professores quase não terem mencionado esse tipo de imitação, isso não significa, necessariamente, que ela não exista, mas também que, se isso ocorre, eles não a julgam relevante, o que pode significar uma boa aceitação dos alunos com deficiência intelectual por seus pares.

Na Tabela 4, estão as freqüências de respostas dos entrevistados quanto à percepção que têm de os alunos sem deficiência intelectual se julgarem superiores aos que a possuem.

Tabela 4. Respostas dos professores à pergunta se os alunos sem deficiência se julgavam superiores àqueles com deficiência.

\begin{tabular}{llllll}
\hline & G1 & G2 & G3 & G4 & Total \\
\hline Sim & 1 & 2 & 2 & 2 & 7 \\
Não & 2 & 0 & 0 & 0 & 2 \\
Não cita & 1 & 1 & 2 & 1 & 5 \\
Total & 4 & 3 & 4 & 3 & 14 \\
\hline
\end{tabular}

Conforme os dados da Tabela 4, pode-se verificar que metade dos professores avalia que os alunos sem deficiência intelectual se sentem superiores aos que não a têm, e dois avaliam que isso não ocorre. Nessa questão, também foi grande a proporção dos entrevistados que não se manifestou. Mais da metade dos professores que, em suas entrevistas, indicou haver esse sentimento de superioridade não tem experiência com alunos com deficiência intelectual, de modo que tal resposta diz respeito às suas expectativas. Dessa forma, podemos dizer que, dos que têm experiência com educação inclusiva, menos da metade percebe a existência desse sentimento. É notável que, entre os que responderam que não há o sentimento de superioridade por parte dos alunos sem deficiência intelectual em relação aos que a têm, estão professores de escolas particulares com experiência (G1) que, talvez, devido ao menor número de alunos em sala, consigam observar melhor seus alunos ou então trabalhar melhor a relação entre os dois tipos de alunos. A existência do sentimento de superioridade pode implicar uma forma de negar a identificação: o que é considerado mais frágil - o aluno com deficiência - suscitaria a lembrança da fragilidade vivida no passado e aparentemente superada, que deve ser negada em uma cultura que valoriza a força (ver Crochík, 2006). Considerando que os professores do G2 
e do G4 não têm experiência com esse tipo de educação, o esclarecimento em relação a essa questão pode ser valioso para que se, e quando, puderem ter essa experiência possam atuar de forma a compreender e combater esse sentimento.

Na Tabela 5, encontram-se as freqüências das respostas dos entrevistados a respeito de julgarem que os alunos com deficiência intelectual podem ou não atrapalhar a aula.

Tabela 5. Percepção dos professores em relação ao fato de os alunos com deficiência atrapalharem a aula.

\begin{tabular}{llllll}
\hline & G1 & G2 & G3 & G4 & Total \\
\hline Sim & 2 & 2 & 2 & 1 & 7 \\
Não & 2 & 1 & 2 & 2 & 7 \\
Não cita & 0 & 0 & 0 & 0 & 0 \\
Total & 4 & 3 & 4 & 3 & 14 \\
\hline
\end{tabular}

A Tabela 5 mostra que metade dos entrevistados considera que a presença dos alunos com deficiência intelectual atrapalha o processo de aprendizagem dos alunos sem essa deficiência, e a outra metade considera que não atrapalha; uma divisão similar ocorre em cada um dos grupos, e todos os entrevistados explicitaram sua posição em relação a essa questão.

Os dados da pesquisa citada anteriormente (Klingner \& Vaughn, 1999) fortalecem a posição dos discordantes, posto que evidenciam que os alunos sem deficiência aprendem a auxiliar o professor a ensinar os que têm deficiência. Além disso, segundo Monteiro e Castro (1997), pesquisas mostram que os alunos sem deficiência tendem a se tornar mais solidários. Esses dados indicam um ponto central do debate sobre a educação inclusiva, que não pode deixar de ser explicitado. Por outro lado, a divisão das opiniões encontradas pode indicar a pouca discussão acerca da educação inclusiva em nosso meio.

É interessante acrescentarmos a essa discussão o fato de que cinco dos entrevistados, a maioria de escolas particulares com experiência com educação inclusiva, citaram espontaneamente a existência de ciúmes dos alunos sem deficiência intelectual em relação aos que a possuem, o que pode significar que a necessidade de mais cuidados dirigidos aos alunos com deficiência intelectual nessas escolas suscitaria esse sentimento em seus colegas. Isso fortalece a suposição em relação aos dados das tabelas anteriores: se os alunos com deficiência intelectual são considerados mais frágeis e suscitam identificação que deve ser negada, os ciúmes podem implicar o desejo de voltar aos tempos passados, quando o cuidado e a atenção dos adultos eram mais freqüentes.

\section{Condições necessárias à implementação da educação inclusiva}

Na Tabela 6, encontram-se as respostas dos entrevistados em relação às condições necessárias para a implementação da educação inclusiva. 
Tabela 6. Condições consideradas necessárias para a implementação da educação inclusiva.

\begin{tabular}{llllll}
\hline & G1(4) & G2(3) & G3(4) & G4(3) & Total (14) \\
\hline Rec. hum. & 3 & 3 & 3 & 0 & 9 \\
Pol. pub. & 1 & 0 & 2 & 1 & 4 \\
Cond. mater. & 1 & 2 & 1 & 1 & 5 \\
Geral/outras & 1 & 0 & 0 & 2 & 3 \\
Total* & 6 & 5 & 6 & 4 & 21 \\
\hline
\end{tabular}

*Refere-se ao número de respostas, e não ao de sujeitos

Pelos dados da Tabela 6, pode-se verificar que a condição objetiva mais citada para a implementação da educação inclusiva refere-se aos recursos humanos; menor quantidade de professores se refere às condições materiais e às políticas públicas. Ainda que não conste na Tabela, cabe mencionar que um sujeito do G1 não citou nenhuma dessas condições.

Esse é um resultado importante, pois se o problema principal são os recursos humanos, a questão se vê circunscrita à formação e à contratação de profissionais, isto é, depende da decisão e das possibilidades da escola. Devemos, no entanto, ressaltar que os professores indicaram a importância das políticas públicas e das condições materiais. Como foram poucas as respostas que se referiram a condições sociais (outras), a forma de pensar dos entrevistados em relação a essa questão parece se vincular prioritariamente a questões organizacionais e formais (políticas públicas), mas pouco a condições sociais favoráveis e desfavoráveis à implementação desse tipo de educação, tais como descritas na introdução deste artigo.

Considerando que os professores se posicionaram, em sua maioria, a favor da educação inclusiva (ver Tabela 2), podemos inferir que, para eles, não cabe mais a discussão em relação a se deve ou não ser implementada tal tipo de educação. Nesse sentido, talvez considerem adequadas as políticas públicas estabelecidas, e não a questão material como a principal, posto que entendem que a questão principal se deva à própria educação: currículo, métodos e conhecimentos. Se isso for verdade, os principais obstáculos se referem às condições de aula, à formação e ao auxílio de especialistas, que serão analisados nas tabelas a seguir.

As posições dos professores quanto à limitação do número de alunos por classe ser ou não um fator importante para a implementação da educação inclusiva se encontra na Tabela 7.

Tabela 7. Posição dos professores em relação a um limite no número de alunos em sala de aula.

\begin{tabular}{llllll}
\hline & G1 & G2 & G3 & G4 & Total \\
\hline Sim & 3 & 2 & 4 & 2 & 11 \\
Não restringe & 0 & 0 & 0 & 1 & 1 \\
Não cita & 1 & 1 & 0 & 0 & 2 \\
Total & 4 & 3 & 4 & 3 & 14 \\
\hline
\end{tabular}


Quanto ao número máximo (não necessariamente especificado) de alunos (com e sem deficiência) em sala de aula, como se pode observar na Tabela 7, a maioria dos entrevistados declarou ser esse um fator importante, exceto por um professor de escola pública sem experiência (G4), que declarou não achar essa restrição necessária, e dois professores de escolas particulares, com (G1) e sem experiência (G2), que não manifestaram o seu posicionamento em torno desse ponto.

Tal como Beyer (2005) relata acontecer na Alemanha, onde diminuem o número de alunos em sala de aula regular em função da incorporação de alunos com deficiência, os professores entrevistados, independentemente do grupo ao qual pertencem, também são favoráveis a essa diminuição. Como quase não houve diferenças entre os professores de escolas públicas ou particulares, pode-se inferir que há quase o consenso de que o aluno com deficiência necessitará de mais atenção e dedicação do professor para cumprir os mesmos objetivos anteriores à inclusão. Provavelmente, essa restrição deveria ser feita pelos professores, independentemente de o foco ser a educação inclusiva, e indica a preferência por um tipo de ensino no qual o acompanhamento mais individualizado possa ser feito, o que faz parte das propostas da educação inclusiva, indicando que esta não diz respeito somente aos alunos antes segregados da escola, mas também aos que não o são.

Na Tabela 8, encontram-se os dados a respeito da posição dos entrevistados em relação ao limite que estabelecem ao número de alunos com deficiência intelectual em sala de aula.

Tabela 8. Restrição dos professores ao número de alunos com deficiência intelectual em sala de aula.

\begin{tabular}{llllll}
\hline & G1 & G2 & G3 & G4 & Total \\
\hline Sim & 3 & 2 & 4 & 1 & 10 \\
Não restringe & 0 & 1 & 0 & 1 & 2 \\
Não cita & 1 & 0 & 0 & 1 & 2 \\
Total & 4 & 3 & 4 & 3 & 14 \\
\hline
\end{tabular}

Quanto à restrição acerca de um número máximo (não necessariamente especificado) de alunos com deficiência intelectual em sala de aula, segundo a Tabela 8, pode-se observar que a maioria elege essa restrição como importante: 10 de 14 entrevistados. Não houve distinção notável entre os grupos. Essa não é uma condição que deponha contra a implementação da educação inclusiva, uma vez que é difícil negar que alunos com deficiência intelectual, em geral, necessitem mais atenção por parte dos educadores, desde que esses estejam envolvidos. Certamente, conforme citamos na introdução, a experiência relatada por Pacheco et al. (2007) não impõe esse limite. De todo modo, como são poucos os alunos com deficiência em relação ao total de alunos, se eles estiverem em diversas classes, e em cada uma houver poucos deles, talvez seja maior a probabilidade de evitar a segregação ou a marginalização desses alunos, devido à possibilidade de mais alunos terem contato com eles. Deve-se ressaltar, contudo, que, na posição que consideramos mais avançada em relação à educação inclusiva, representada pelos autores acima citados, por Booth e Ainscow (2002) e, em nosso meio, por Mantoan (2003), não deve haver considerações prévias em relação a esse fator. 
As posições dos entrevistados acerca da necessidade de o professor ser especialista para poder trabalhar com alunos com deficiência intelectual em sua sala estão expostas na Tabela 9.

Tabela 9. Respostas dos entrevistados sobre a necessidade de o professor ser especialista em educação inclusiva.

\begin{tabular}{llllll}
\hline & G1 & G2 & G3 & G4 & Total \\
\hline Sim & 2 & 2 & 3 & 1 & 8 \\
Não & 2 & 0 & 0 & 2 & 4 \\
Não cita & 0 & 1 & 1 & 0 & 2 \\
Total & 4 & 3 & 4 & 3 & 14 \\
\hline
\end{tabular}

No que tange à necessidade de o professor ser um especialista em educação inclusiva, segundo a Tabela 9, pode-se observar que 8 em 14 consideram essa uma condição importante. É interessante observar que, se não considerarmos os dois entrevistados que não se manifestaram, há uma tendência de os sujeitos do G2 e do G3 assinalarem essa condição e a de os dos outros grupos se dividirem em relação a ela. Talvez as diferentes condições entre as escolas públicas e as particulares possam explicar essa tendência: os professores sem experiência em educação inclusiva de escolas particulares, uma vez que têm, em princípio, condições mais adequadas, podem afirmar que não há necessidade de o professor ser especialista, ao passo que os de escola pública com experiência defendem a especialização, não em função do novo tipo de aluno, mas porque as condições pouco adequadas não favorecem um suposto atendimento diferençado, que passa a se expressar na necessidade de se ter mais recursos de formação para se conseguir atuar na educação inclusiva. Em relação aos sujeitos do G2, talvez a falta de experiência nesse tipo de educação leve a supor que seja necessária a presença de um especialista.

Novamente, devemos ressaltar que, pela literatura que consideramos mais avançada na área, não se requer que o professor tenha uma formação diferençada em relação aos novos alunos que a educação inclusiva agrega; ainda que, tal como propõe Pacheco et al. (2007), as informações necessárias podem ser pesquisadas após se ter experiência, e não necessariamente antes. Isso, a nosso ver, ajuda a evitar possíveis preconceitos em relação aos alunos a serem incluídos, posto que, até o momento, as pesquisas mostram que não há distinção no desenvolvimento e aprendizado (afora o fato de serem mais lentos e apresentarem mais dificuldades) dos alunos que têm deficiência intelectual e os que não a têm, e assim, não há porque haver uma formação especial para a educação inclusiva.

A Tabela 10 traz a freqüência de respostas dos entrevistados a respeito da necessidade de especialista de apoio na educação inclusiva.

Tabela 10. Respostas dos professores em relação à necessidade de especialista de apoio.

\begin{tabular}{llllll}
\hline & G1 & G2 & G3 & G4 & Total \\
\hline Sim & 4 & 2 & 4 & 2 & 12 \\
Não & 0 & 0 & 0 & 0 & 0 \\
Não cita & 0 & 1 & 0 & 1 & 2 \\
Total & 4 & 3 & 4 & 3 & 14 \\
\hline
\end{tabular}


Quanto à necessidade de um especialista de apoio, como se pode observar na Tabela 10, todos os entrevistados declararam considerar ser esse um recurso importante para a educação inclusiva, exceto dois professores, ambos sem experiência, um de escola particular (G2) e outro de escola pública (G4), que não explicitaram o posicionamento frente a esse ponto.

Profissionais (médicos, fonoaudiólogos, fisioterapeutas, terapeutas ocupacionais, psicólogos) externos e/ou internos podem auxiliar o desenvolvimento do aluno, não exclusivamente alunos com deficiência intelectual. Assim, essa não é, a nosso ver, uma restrição que os entrevistados fazem à educação inclusiva. É importante destacar que os profissionais considerados necessários deveriam dar apoio ao professor, e não exercerem o papel central, o que fortalece a mudança da perspectiva médica para a pedagógica apontada por Jannuzzi (2004). Isso permite fortalecer o papel do professor nesse tipo de educação.

Os dados da Tabela 11 dizem respeito à necessidade, percebida pelos entrevistados, de terem, na educação inclusiva, um auxílio em sala de aula.

Tabela 11. Posição dos professores acerca da necessidade do auxílio de outro professor em sala de aula.

\begin{tabular}{llllll}
\hline & G1 & G2 & G3 & G4 & Total \\
\hline Sim & 2 & 3 & 3 & 0 & 8 \\
Não & 1 & 0 & 0 & 0 & 1 \\
Não cita & 1 & 0 & 1 & 3 & 5 \\
Total & 4 & 3 & 4 & 3 & 14 \\
\hline
\end{tabular}

Segundo os dados da Tabela 11, dos que explicitaram a posição a respeito da necessidade de apoio em sala de aula na educação inclusiva, apenas um afirma não ser necessário. Chama a atenção também o fato de cinco entrevistados não terem se posicionado frente a esse tema, sendo que três deles não possuem experiência em educação inclusiva e são professores de escolas públicas. Beyer (2005) e Pacheco et al. (2007) acentuam, em relação à discussão em educação inclusiva, que o trabalho conjunto entre professores é importante nessa área, o que também já preconizavam Booth e Ainscow (2002). Não se trata, no caso desses autores, da defesa da presença de um auxiliar em sala de aula, mas do trabalho conjunto entre os professores. Por outro lado, deve-se enfatizar que as respostas dos entrevistados não implicam, necessariamente, a presença de um acompanhante pedagógico em sala de aula, o que poderia contribuir com a marginalização e/ou segregação dos alunos com deficiência intelectual, mas parecem fortalecer as posições anteriormente descritas: condições mais adequadas para incorporar alunos com deficiência.

As freqüências das respostas dos professores aos objetivos da educação inclusiva em relação aos alunos com deficiência intelectual encontram-se na Tabela 12.

Tabela 12. Objetivos da educação inclusiva, segundo os professores, em relação aos alunos com deficiência.

\begin{tabular}{llllll}
\hline & G1 & G2 & G3 & G4 & Total \\
\hline Socialização e aprendizagem & 3 & 3 & 2 & 2 & 10 \\
Socialização & & & 2 & & 2 \\
Aprendizagem & 1 & & & & 1 \\
Não cita & & & & 1 & 1 \\
Total & 4 & 3 & 4 & 3 & 14 \\
\hline
\end{tabular}


Dos dados da Tabela 12, pode-se observar que a maioria dos entrevistados julga que a educação inclusiva deva se voltar para a socialização e para a aprendizagem dos alunos com deficiência intelectual. Cabe notar que dois dos quatro professores do G3 (que têm experiência nesse tipo de educação e provêm de escolas públicas) julgam que a escola deva se preocupar apenas com a socialização dos alunos com deficiência intelectual, e um professor do G1 considera que a aprendizagem é o objetivo a ser cumprido com esses alunos. É importante assinalar que os processos relativos à aprendizagem podem implicar ganhos para a socialização de crianças com deficiência intelectual, no entanto, ocupar-se apenas da sua socialização não implica, necessariamente, a melhoria da aprendizagem dos conteúdos escolares. Cabe assinalar, ainda, que um professor do G4 não se manifestou sobre essa questão.

Cabe ressaltar que quase todos os professores da amostra que atuam em escolas privadas pensam ser importante atentar para a socialização e para a aprendizagem dos alunos com deficiência intelectual. Não ocorre o mesmo entre os professores que atuam na escola pública, pois dois de seus professores entrevistados entendem que só a socialização seja suficiente. Essa distinção pode ser devida às diferentes formas de conduzir a discussão acerca da educação inclusiva. Talvez essa discussão nas escolas particulares, às quais parte de nossos professores pertence, possa ser mais aprofundada do que nas públicas. Devemos lembrar que as escolas que pesquisamos não são representativas do total de escolas, e que, assim, deve haver escolas particulares nas quais essa discussão não seja feita e escolas públicas que a tenham desenvolvido com profundidade. De todo modo, devemos acentuar que a educação, segundo Adorno (1967/1995), também deve se voltar para a adaptação, e essa envolve não só a socialização, que é relevante, mas também o desenvolvimento de habilidades e o aprendizado de conteúdos, necessários para a participação na sociedade. Assim, não é de menor importância que a maioria dos professores entrevistados considere que ambas são necessárias. É claro, também segundo Adorno, que a educação deve ir além da adaptação, e a discussão e a prática da educação inclusiva podem contribuir para isso na medida em que combatem a discriminação; caberia a elas mostrar como essa desigualdade é gerada socialmente.

\section{Considerações finais}

Apesar de ser pequeno o número de professores entrevistados, os dados obtidos indicam as tendências existentes na atual discussão sobre a educação inclusiva. Como a educação inclusiva faz parte de um movimento mais amplo de inclusão social, conforme afirmamos no início deste texto, os dados obtidos na pesquisa revelam contradições acerca dessa inclusão. Os professores tendem a ser favoráveis à educação inclusiva; de uma forma geral, não apresentaram obstáculos intransponíveis para a sua implementação, ao mesmo tempo em que tendem a julgar necessária uma formação especializada na área, como se os novos alunos ingressantes na classe regular fossem substancialmente distintos dos alunos sem deficiência.

A questão posta não nega que novas dificuldades podem surgir das diferenças significativas desses novos alunos, mas tem como preocupação eles serem considerados obstáculos antes da experiência, o que indicaria uma atitude preconceituosa. Além disso, parece reforçar a tendência presente na educação escolar de que, ao partir do pressuposto da homogeneidade da capacidade dos alunos, quando esses não respondem adequadamente, atribui a responsabilidade da 
"falha" a eles, que então são encaminhados a especialistas. Nesse sentido, a proposta de Booth e Ainscow (2002) de substituir a expressão "alunos portadores de deficiência" por "obstáculos escolares ao aprendizado" traz um deslocamento importante da maneira de se enfrentar os problemas educacionais, não somente os relacionados à educação inclusiva.

O fato de os professores entrevistados declararem, em sua maioria, que o objetivo da escola com os alunos com deficiência intelectual não é unicamente o de socialização, mas também o de aprendizado pode ser considerado um dado importante: a igualdade frente à possibilidade de aprender, apesar das diferenças, é um marco em uma sociedade democrática. Certamente, essa diferença inicial não desaparece, mas pode estar presente de maneira a permitir que todos possam participar da sociedade. Um dos objetivos da educação é o de transmitir a cultura para permitir que os alunos possam expressar suas necessidades e desejos de forma universal, mas note-se que a forma é universal: o que ela traz pode e deve ser compartilhado coletivamente sem se descuidar da particularidade. Assim, em relação à questão da normalização, pode- se dizer que normas, no que contêm de universal (e este se modifica historicamente), são importantes para que as expressões particulares, possíveis também devido a elas, possam inclusive indicar sua inadequação, mas isso deve ocorrer após a sua incorporação, e não antes; sem o aprendizado das normas da comunicação, por exemplo, o que é dito dificilmente poderia ser compreendido. Deve-se assinalar que essas normas não se referem às considerações estatísticas, mas a regras e a princípios. A defesa da especialização em educação inclusiva, por parte de alguns professores entrevistados neste estudo, afirma a normatização estatística. O que propomos é que as regras e princípios devem ser compartilhados por todos, e, quando necessário, superados.

O movimento de inclusão social presente na educação inclusiva, pelos dados obtidos na pesquisa aqui relatada, está se fortalecendo; pelo fato de se desenvolver em uma sociedade contraditória, abriga em si mesmo essas contradições, que não devem ser ocultadas, mas, ao contrário, devem ter seus limites considerados, para que os avanços não sejam menosprezados nem tampouco exaltados.

José Leon Crochík*

Professor titular do Instituto de Psicologia da USP e bolsista do CNPq.

Cintia C. Freller

Doutora em Psicologia, psicóloga do Instituto de Psicologia da USP.

Marian Ávila de Lima e Dias

Doutora em Psicologia, professora da Universidade Presbiteriana Mackenzie.

Marisa Feffermann

Doutora em Psicologia, pesquisadora do Instituto de Saúde/SES/SP.

Rafael Baioni do Nascimento

Pós-graduando no Programa de Psicologia Escolar e do Desenvolvimento Humano do Instituto de Psicologia da USP.

Ricardo Casco

Doutor em Educação pela Pontifícia Universidade Católica de São Paulo.

*Endereço para envio de correspondência:

Av. Prof. Mello Moraes, 1721 Cidade Universitária. Cep: 05508-900 São Paulo - SP.

E-mail: jlchna@usp.br

Recebido 18/12/2007; Reformulado 20/08/2008; Aprovado 24/08/2008. 


\section{Referências}

Adorno, T. W. (1972). Teoría de la seudocultura In T. W. Adorno, Filosofía y superstición (pp. 141-174). Madrid: Alianza Editorial. (Trabalho original publicado em 1959)

Adorno, T. W. (1995). Educação após Auschwitz. In T. W. Adorno, Educação e emancipação (pp. 119-138). Rio de Janeiro: Paz e Terra. (Trabalho original publicado em 1967)

Adorno, T. W. (1995). Educação e emancipação. In T. W. Adorno, Educação e emancipação (pp. 119-138). Rio de Janeiro: Paz e Terra. (Trabalho original publicado em 1969)

Adorno, T. W. (1995). Educação para quê? In T. W. Adorno, Educação e emancipação. Rio de Janeiro: Paz e Terra. (Trabalho original publicado em 1967)

Adorno, T. W. (1995). Progresso. In T. W. Adorno, Palavras e sinais (pp. 37-61). Petrópolis, RJ: Vozes. (Trabalho original publicado em 1964)

Apple, M. W. (2002). Podem as pedagogias críticas sustar as políticas de direita? Cadernos de Pesquisa (116), 107-142.

Beyer, H. O. (2005). Inclusão e avaliação na escola. Porto Alegre: Mediação.

Benjamin, W. (1989). Sobre alguns temas em Baudelaire. In Charles Baudelaire: um lírico no auge do capitalismo (J. Martins Barbosa \& H. Alves Baptista, trads.). São Paulo: Brasiliense. (Trabalho original publicado em 1938)

Booth, T., \& Ainscow, M. (2002). Index para a inclusão (Reino Unido: CSIE, 2002. Versão produzida e traduzida pelo LAPEADE - Laboratório de Pesquisa, Estudos e Apoio à Participação e à Diversidade em Educação). Rio de Janeiro: Universidade Federal do Rio de Janeiro.

Casco, R. (2007). Autoridade e formação: relações sociais na sala de aula e no recreio. Tese de Doutorado em Educação: História, Política e Sociedade, Pontifícia Universidade Católica de São Paulo, São Paulo.

Cook, B. G., Tankersley, M., Cook, L., \& Landrun, T. J. (2000). Teacher's attitudes toward their included students with disabilities. Exceptional Children, 67(1), 115-135.

Crochík, J. L. (2006). Preconceito, indivíduo e cultura (3a ed.). São Paulo: Casa do Psicólogo.

Crochík, J. L., Ferrari, M. A. L. D., Hryniewicz, R. R., Barros, O. N., \& Nascimento, R. B. (2006). Preconceito e atitudes em relação à educação inclusiva. Psicologia Argumento, 24(46), 55-70.

Freud, S. (1969). O mal-estar na civilização. In S. Freud, Edição standard brasileira das obras psicológicas completas de Sigmund Freud. Rio de Janeiro: Imago. (Trabalho original publicado em 1930)

Horkheimer, M., \& Adorno, T. W. (1978). Preconceito. In Temas básicos de sociologia (pp.172-183). São Paulo: Cultrix.

Horkheimer, M., \& Adorno, T. W. (1985). Dialética do esclarecimento. Rio de Janeiro: Jorge Zahar. (Trabalho original publicado em 1947)
Jannuzzi, G. M. (2004). Educação do deficiente no Brasil. São Paulo: Autores Associados.

Klingner, J. K., \& Vaughn, S. (1999). Student's perceptions of instruction in inclusion classrooms: Implications for students with learning disabilities. Exceptional Children, 66(1), 23-37.

León, M. J. (1994). La perspectiva del profesor tutor sobre los problemas de la integración de los niños con necesidades educativas especiales. Revista de Educación Especial, (18), 77-83.

Lessa, C. et al. (1997). Pobreza e política social: a exclusão nos anos 90. Praga: Estudos Marxistas, ano1(3), 63-87.

Mantoan, M.T.E. (2003). Inclusão escolar. O que é? Por quê? Como fazer? São Paulo: Moderna.

Marcuse, H. (1981). Eros e civilização: uma interpretação filosófica do pensamento de Freud (8a ed., Á. Cabral, trad.). Rio de Janeiro: Zahar. (Trabalho original publicado em 1955)

Marcuse, H. (1982). Ideologia da sociedade industrial. Rio de Janeiro: Zahar. (Trabalho original publicado em 1964)

Martins, J. S. (1997). Exclusão social e a nova desigualdade. São Paulo: Paulus.

Marx, K. (1984). O capital: crítica da economia política (Livro I, Vol. 1). São Paulo: Difel. (Trabalho original publicado em 1867)

Mittler, P. (2003). Educação inclusiva: contextos sociais. Porto Alegre: Artmed.

Monteiro, M. B., \& Castro, P. (1997). Cada cabeça sua sentença. Oeira: Celta.

Pacheco, J., Eggertsdóttir, R., \& Marinósson, G. L. (2007). Caminhos para a inclusão. Porto Alegre: Artmed.

Sans del Rio, S. (1996). Integración de alumnos con necesidades educativas especiales: panorama internacional. Madrid: Artegraf.

Vala, J., \& Monteiro, M. B. (1996). Psicologia social. Lisboa: Fundação Calouste Gulbenkian.

Vivarta, V. (2003). Mídia e diversidade. Brasília, DF: ANDI/ Fundação Banco do Brasil.

Zibas, D. M. L. (1999). A reforma educacional espanhola: entrevista com Mariano Enguita e Gimeno Sacristán. Cadernos de Pesquisa da Fundação Carlos Chagas, (108), 233-248. 